\title{
Identification and engineering of 32 membered antifungal macrolactone notonesomycins
}

\author{
Falicia Goh ${ }^{1,7}$, Mingzi M. Zhang ${ }^{2,8}$, Tian Ru Lim' ${ }^{1}$ Kia Ngee Low ${ }^{1}$, Choy Eng Nge1, Elena Heng ${ }^{3}$, Wan Lin Yeo², \\ Fernanda L. Sirota ${ }^{1}$, Sharon Crasta ${ }^{1}$, Zann Tann', Veronica Ng${ }^{1}$, Chung Yan Leong ${ }^{1}$, Huibin Zhang ${ }^{4}$, \\ Alexander Lezhava ${ }^{4}$, Swaine L. Chen ${ }^{4,5}$, Shawn S. Hoon ${ }^{3}$, Frank Eisenhaber ${ }^{1,6}$, Birgit Eisenhaber ${ }^{1}$, \\ Yoganathan Kanagasundaram ${ }^{1}$, Fong T. Wong ${ }^{3^{*}}$ and Siew Bee Ng ${ }^{1 *}$
}

\begin{abstract}
Notonesomycin A is a 32-membered bioactive glycosylated macrolactone known to be produced by Streptomyces aminophilus subsp. notonesogenes 647-AV1 and S. aminophilus DSM 40186. In a high throughput antifungal screening campaign, we identified an alternative notonesomycin A producing strain, Streptomyces sp. A793, and its biosynthetic gene cluster. From this strain, we further characterized a new more potent antifungal non-sulfated analogue, named notonesomycin B. Through CRISPR-Cas9 engineering of the biosynthetic gene cluster, we were able to increase the production yield of notonesomycin B by up to 18-fold as well as generate a strain that exclusively produces this analogue.
\end{abstract}

Keywords: Natural product, Polyketide, Biosynthetic gene cluster, CRISPR-Cas9, Sulfation, Streptomyces antibiotic regulatory protein

\section{Introduction}

Natural products (NPs) represent a diverse source of bioactive compounds with clinical relevance, as evidenced by the fact that half of current drugs are NP or NP-derived [1,2]. They can be further engineered to best suit various clinical, flavor and agrochemical applications $[3,4]$. The A*STAR Natural Organism Library (NOL) [5] is a Singapore-based collection of over 120,000 microbial strains, which include 58,000 actinomycetes collected from diverse habitats. Previous screening of this collection has uncovered a number of bioactive compounds,

\footnotetext{
*Correspondence: wongft@ibn.a-star.edu.sg; ngsb@bii.a-star.edu.sg

${ }^{1}$ Bioinformatics Institute, A*STAR, 30 Biopolis Street, \#07-01 Matrix,

Singapore 138671, Singapore

${ }^{3}$ Molecular Engineering Laboratory, Institute of Bioengineering

and Nanotechnology, A*STAR, 31 Biopolis Way, Nanos, Singapore 138669, Singapore

Full list of author information is available at the end of the article
}

including antibacterial compounds microsphaerins A-D [6], gargantulide A [7], and anthracimycin [8], and antagonists of the human CCR5 receptor; fuscinarin, fuscin, and cochlioquinones [9].

Candida species are common pathogens associated with invasive fungal diseases contributing to high disease burden [10-12]. Increasing number of immunocompromised patients [13], emerging new fungal infections [14] and drug-resistant fungal pathogens $[15,16]$ have rekindled interest in new antifungal therapeutics. Bioactivity-guided profiling of NOL extracts against Candida albicans uncovered the 32-membered macrolactone notonesomycin A (Fig. 1). Known to have antifungal property, notonesomycin A was first reported in Streptomyces aminophilus subsp. notonesogenes 647-AV1 in 1986 [17], from an assay against rice sheath blight disease. Characterization of similar compounds, such as brasilinolides [18, 19], ibomycin [20], langkolide [21], 

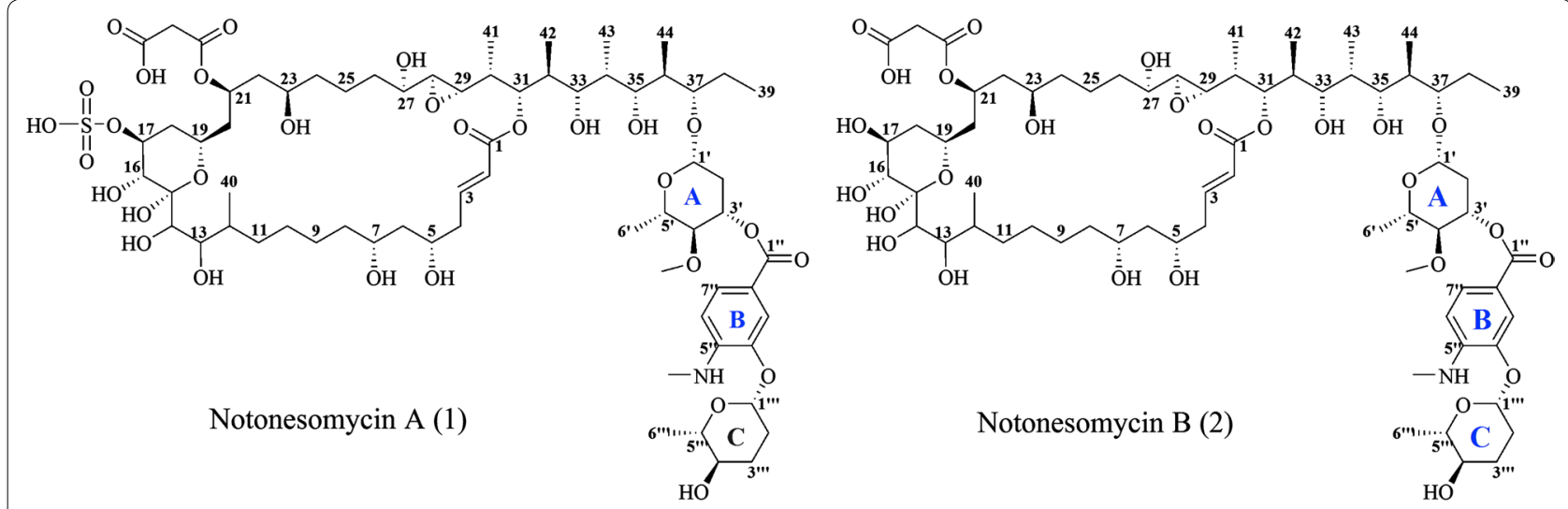

Fig. 1 Structures of notonesomycins A (1) and B (2)

novonestmycins A and B [22], PM100117 and PM100118 $[23,24]$, demonstrates the bio-versatility of these $32-36$ membered macrolactones. For this family of compounds, immunosuppressive, anti-tumor, and antifungal bioactivities have been reported. A major difference between these macrolactones and notonesomycin $\mathrm{A}$ lies in the addition of a sulfate group at position $\mathrm{C}-17$ by $\mathrm{O}$-sulfation, which is a modification seen in a limited number of microbial natural products. Interestingly, we also identified for the first time, a non-sulfated bioactive analogue of notonesomycin A, henceforth named notonesomycin B (Fig. 1).

Advances in DNA sequencing and sequence analysis have driven deeper genomic insights into streptomycetes $[25,26]$. In addition, genetic engineering of previously challenging strains is now possible with CRISPR-Cas9 [27-31]. Combining the understanding of biosynthetic gene clusters (BGCs) and improved ability to edit streptomycete genomes, combinatorial engineering of analogue libraries for the purpose of producing a final therapeutically relevant product can now be accomplished at a faster pace.

In this study, we present the characterization of notonesomycin BGC from Streptomyces sp. A793 as well as the isolation of a new non-sulfated notonesomycin analogue. We also demonstrated the application of CRISPR-Cas9 in Streptomyces sp. A793 to increase the production of the more bioactive non-sulfated notonesomycin B.

\section{Results}

Isolation and identification of notonesomycins

A (1) and a new analogue notonesomycin B (2) from Streptomyces sp. A793

From bioactivity based profiling of NOL strain library, extracts generated from Streptomyces sp. A793 were active against Candida albicans. Further bioassay-guided isolation and identification of compounds from Streptomyces sp. A793 led to the isolation and characterization of 2 compounds $(\mathbf{1}, \mathbf{2})$.

Compound 1 (Fig. 1, Additional file 1: Figure S1) was isolated as a brownish amorphous solid with $[\alpha]_{\mathrm{D}}-25$ (c $0.9, \mathrm{MeOH})$. ESI-MS showed an $[\mathrm{M}+\mathrm{H}]^{+}$peak at $\mathrm{m} / \mathrm{z} 1454$ and the HR-ESI-MS measurement established the molecular formula as $\mathrm{C}_{68} \mathrm{H}_{111} \mathrm{NO}_{30} \mathrm{~S}$. The ${ }^{13} \mathrm{C}$ NMR data (Additional file 1: Table S1 and Figure S2) showed a total of 68 carbon resonances, comprising 4 carbonyl $(\delta 167.9,168.4,170.5,172.3)$, eight olefinic ( $\delta 109.1$, $116.9,117.2,124.4,127.5,144.8,146.9,148.5)$, three carbons bonded to 2 heteroatoms $(\delta 98.2,99.1,102.6)$, 21 oxymethine $(\delta 60.3-85.6)$, five methine $(\delta 36.0,38.3$, $38.6,40.2,40.5), 17$ methylene $(\delta 22.7-44.4)$, one methoxy $(\delta 61.1)$, one $N$-methyl $(\delta 29.8)$, and eight methyl $(\delta$ $4.8,9.5,10.4,11.1,14.4,15.3,17.5,18.4)$ carbon atoms. The ${ }^{1} \mathrm{H}$ NMR spectrum (Additional file 1: Table S1 and Figure S3) showed the presence of three aromatic signals $[\delta 7.63(\mathrm{~d}, J=2 \mathrm{~Hz}), 6.58(\mathrm{~d}, J=9 \mathrm{~Hz}), 7.68(\mathrm{dd}, J=9$, $2 \mathrm{~Hz}$ )], indicating a tri-substituted aromatic ring system. The remaining two olefinic proton signals resonated at $\delta 5.95$ and 7.04 with a large coupling constant of $15 \mathrm{~Hz}$ suggesting a $E$ configuration and were assigned to an $\alpha$, $\beta$-unsaturated ester group based on the observed $\delta_{\mathrm{H}} 5.95$ $(\mathrm{H}-2)$ and $7.04(\mathrm{H}-3)$ to $\delta_{\mathrm{C}} 168.4(\mathrm{C}-1)$ HMBC correlations (Additional file 1: Figure S1). Two downfield methyl singlets observed at $\delta 3.50$ and 2.87 (3 protons) were assigned to the $O$-methyl and $N$-methyl, respectively. Eight methyl signals were observed at $\delta 0.76(\mathrm{~d}, J=7 \mathrm{~Hz})$, $0.84(\mathrm{~d}, J=7 \mathrm{~Hz}), 0.90(\mathrm{~d}, J=7 \mathrm{~Hz}), 0.96(\mathrm{~d}, J=7 \mathrm{~Hz}), 0.97$ $(\mathrm{t}, J=7 \mathrm{~Hz})$, and $1.06(\mathrm{~d}, J=7 \mathrm{~Hz}), 1.27(\mathrm{~d}, J=7 \mathrm{~Hz})$, and $1.32(\mathrm{~d}, J=6 \mathrm{~Hz})$ and were assigned to $\mathrm{H}-44, \mathrm{H}-42, \mathrm{H}-43$, $\mathrm{H}-40, \mathrm{H}-39, \mathrm{H}-41, \mathrm{H}-6^{\prime \prime \prime}$ and $\mathrm{H}-6^{\prime}$, respectively. The two oxymethines observed at $\delta_{\mathrm{H}} 2.79\left(\delta_{\mathrm{C}} 63.8\right)$ and $2.73\left(\delta_{\mathrm{C}}\right.$ $-60.3)$ were characteristic of an epoxide moiety with 
cis-orientation based on the observed small coupling constant of $2 \mathrm{~Hz}[32,33]$. The anomeric protons of the two deoxysugar moieties were deduced from the observed doublet and doublet of doublets signals at $\delta_{\mathrm{H}} 4.64$ and 5.11 based on COSY, HSQC and HMBC NMR data (Additional file 1: Figures S4-S6). The two deoxysugar units were linked together by the trisubstituted benzene ring $\mathrm{B}$ via ester group to deoxysugar ring $\mathrm{A}$ from $\mathrm{H}-3^{\prime}$ to $\mathrm{C}-1^{\prime \prime}$ and ether linkage of ring $\mathrm{B}$ to deoxysugar ring $\mathrm{C}$ from $\mathrm{H}-1^{\prime \prime \prime}$ to $\mathrm{C}-4^{\prime \prime}{ }^{3} J \mathrm{HMBC}$ correlations (Additional file 1: Figures S1, S6). The attachment of deoxysugar ring A to $\mathrm{C}-37$ was evident from anomeric proton $(\mathrm{H}-1)$ to C-37 HMBC correlation. Presence of malonate ester was confirmed by two carbonyl signals at $\delta_{\mathrm{C}} 170.5$ and 172.3 but the isolated methylene signals $\left(\delta_{\mathrm{H}} 3.17\right.$ and $\left.\delta_{\mathrm{C}} 43.0\right)$ were observed only in DMSO- $d_{6}$ and not in methanol- $d_{4}$ due to deuterium exchange $[17,34]$. The placements of malonate ester group and the remaining sulfate group at C-21 [34, 35] and C-17 [32], were assigned based on the observed carbon values of $\delta_{C} 71.0$ and 78.2, respectively. From 1D and 2D NMR data, compound 1 was a 32-membered macrocyclic lactone (HMBC: from $\mathrm{H}-31$ to lactone carbonyl) consisting of a sulfate group, a malonate ester, an epoxide, a trisubstituted benzene ring and 2 deoxysugar moieties similar to that of notonesomycin A. In addition, the ${ }^{1} \mathrm{H}$ and ${ }^{13} \mathrm{C}$ NMR data of $\mathbf{1}$ were consistent with those reported for notonesomycin A [17, 34]. Hence, $\mathbf{1}$ was identified as notonesomycin A.

Compound 2 (Fig. 1) was isolated as a white amorphous solid with $[\alpha]_{D}-56$ (c 1.3, MeOH). ESI-MS showed an $[\mathrm{M}+\mathrm{H}]^{+}$peak at $m / z 1374$ and the HR-ESIMS measurement established the molecular formula as $\mathrm{C}_{68} \mathrm{H}_{111} \mathrm{NO}_{27}$. The difference in 80 mass units as compared to 1 suggested a loss of a $\left[\mathrm{SO}_{3}\right]$ group. The ${ }^{1} \mathrm{H}$, ${ }^{13} \mathrm{C}$, COSY, HSQC and HMBC NMR spectra (Additional file 1: Figures S7-S11) indicated the presence of two deoxysugars [ $\delta 4.64(\mathrm{brd}, J=8 \mathrm{~Hz}), \delta 5.11(\mathrm{dd}, J=9$, $2 \mathrm{~Hz})$ ], an epoxide $(\delta 2.72,2.78)$, a trisubstituted benzene ring $[\delta 7.62(\mathrm{~d}, J=2 \mathrm{~Hz}), \delta 6.58(\mathrm{dd}, J=9,2 \mathrm{~Hz}), \delta 5.11$ $(\mathrm{dd}, J=9,2 \mathrm{~Hz})]$, a macrolide incorporating a hemiketal ring, and an $\alpha, \beta$-unsaturated lactone moiety $[\delta 5.95(\mathrm{~d}$, $J=15 \mathrm{~Hz}$ ), $\delta 7.03$ (ddd, $J=15,8,8 \mathrm{~Hz}$ )] similar to those of $\mathbf{1}$. The 1D and 2D NMR (Additional file 1: Figures S7S11) of $\mathbf{2}$ indicated that $\mathbf{1}$ and $\mathbf{2}$ have similar core structures, except for the signals of C-16 $\left(\delta_{\mathrm{H}} 3.63, \delta_{\mathrm{C}} 75.9\right)$, $\mathrm{C}-17\left(\delta_{\mathrm{H}} 3.87, \delta_{\mathrm{C}} 70.0\right)$ and $\mathrm{C}-18\left(\delta_{\mathrm{H}} 1.89,1.25, \delta_{\mathrm{C}} 40.7\right)$ of the 6-membered hemiketal moiety embedded within the macrocyclic ring. Since there was no change in the total number of carbon and protons in $\mathbf{2}$ as compared to $\mathbf{1}$, the observed 80 mass unit loss in HRMS data indicated the presence of a hydroxyl group instead of the sulfate group at $\mathrm{C}-17$. This was further supported by the observed $8.2 \mathrm{ppm}$ upfield shift for C-17 in $2\left(2: \delta_{C}\right.$
70.0; 1: $\left.\delta_{\mathrm{C}} 78.2\right)[36]$ and $\mathrm{HMBC}$ correlation from $\mathrm{H}-16$ to C-17 (Additional file 1: Figures S1, S11). As in 1, the presence of malonate ester group was evidenced by the methylene singlet at $\delta_{\mathrm{H}} 2.91, \delta_{\mathrm{C}} 45.9$ in DMSO- $d_{6} \mathrm{NMR}$ data. Hence, compound 2 was identified as a desulfated derivative of $\mathbf{1}$ and the gross structure of $\mathbf{2}$ is shown in Fig. 1. The relative configurations at most stereogenic centers were determined by comparison with the ${ }^{13} \mathrm{C}$ NMR data of novonestmycins A and B [36] and brasilinolides $A$ and $C$ [33] except for those at $C-5,-7,-12$, -13 , and -14 , which remain unassigned. The relative configurations of $\mathbf{1}$ were assumed to be the same as $\mathbf{2}$ based on high similarity of their NMR data (Fig. 1). 2 is therefore a desulfated derivative of $\mathbf{1}$ and named notonesomy$\operatorname{cin} \mathrm{B}$.

\section{Biological activities of notonesomycins A and B}

Antifungal activities of notonesomycins A and B were determined against $C$. albicans ATCC $^{\circledR} 90028^{\mathrm{TM}}$ and Aspergillus fumigatus ATCC $^{\circledR} 46645^{\mathrm{TM}}$ (Table 1). Compared to notonesomycin $\mathrm{A}$, the non-sulfated notonesomycin $\mathrm{B}$ was four times more active against $A$. fumigatus and five times more active against $C$. albicans. Both compounds were further profiled against commonly used laboratory human cell lines and they displayed $\mathrm{IC}_{50}$ values of $\leq 1 \mu \mathrm{M}$ (Table 1). Between the two compounds, notonesomycin B was three times less active against the tested human cancer cell lines. Both notonesomycins A and B also displayed activity against Staphylococcus aureus Rosenbach $\mathrm{ATCC}^{\circledR} 25923^{\mathrm{TM}}$ with a minimum inhibition concentration of around $20 \mu \mathrm{M}$ (Table 1) but were inactive against tested Gram-negative bacteria.

\section{In silico identification and sequence architecture} of a biosynthetic gene cluster indicative for notonesomycin biosynthesis

Whole-genome sequencing by Pacific Biosciences RS II of Streptomyces sp. A793 yielded a $\sim 8.0 \mathrm{Mb}$ contig and

Table 1 Biological activities of notonesomycins A and B

\begin{tabular}{|c|c|c|}
\hline \multirow[t]{2}{*}{ Target organism or cell line (ATCC ${ }^{\circledR}$ number) } & \multicolumn{2}{|c|}{$\begin{array}{l}\text { Activity }^{a} \\
(\mu \mathrm{M})\end{array}$} \\
\hline & A & B \\
\hline Candida albicans $\left(\right.$ ATCC $\left.^{\circledR} 90028^{\mathrm{TM}}\right)$ & 6.2 & 1.3 \\
\hline Aspergillus fumigatus (ATCC ${ }^{\circledR} 46645^{\mathrm{TM}}$ ) & 16.8 & 4.1 \\
\hline A549 Human lung carcinoma cells (ATCC ${ }^{\circledR}$ CCL-185 $5^{\mathrm{TM}}$ ) & 0.24 & 0.70 \\
\hline $\begin{array}{l}\text { PANC-1 Human pancreas carcinoma cells }\left(\text { ATCC }^{\circledR} \text { CRL- }\right. \\
1469^{\text {TM }} \text { ) }\end{array}$ & 0.25 & 0.74 \\
\hline HepG2 Human liver carcinoma cells (ATCC ${ }^{\circledR} \mathrm{HB}-8065^{\mathrm{TM}}$ ) & 0.26 & 0.72 \\
\hline Staphylococcus aureus Rosenbach $\left(\right.$ ATCC $^{\circledR} 25923^{\mathrm{TM}}$ ) & 19.3 & 18.5 \\
\hline Escherichia coli (ATCC ${ }^{\circledR} 25922^{\mathrm{TM}}$ ) & $>60$ & $>60$ \\
\hline
\end{tabular}

a $\mathrm{IC}_{90}$ for bacterial assays and $\mathrm{IC}_{50}$ for fungi and mammalian cell assay 
an $80 \mathrm{~kb}$ plasmid. The $8.0 \mathrm{Mb}$ contig had a GC content of $72.4 \%$ and within this, 7027 coding sequences and 73 RNAs were identified by RAST (Rapid Annotation using Subsystem Technology, [37]). Based on 16S rRNA sequence alignment, the strain is shown to be closely associated with Streptomyces armeniacus. Analysis by antiSMASH 3.0 [38] identified a $153 \mathrm{~kb}$ BGC with 59 open reading frames indicative for notonesomycin biosynthesis (Fig. 2a). BLASTp against the NCBI non-redundant sequence database [39] was used to annotate the 59 orfs (Additional file 1: Table S2). The polyketide scaffold is encoded by 18 polyketides synthase (PKS) modules within 8 proteins ( $n b c 20,21$ and $n b c 38-43)$, which are consistent with the polyketide backbone of notonesomycin. The putative biosynthetic pathway (order of reactions, extender unit incorporation and tailoring reactions in the polyketide synthases) align mostly with the macrolactone (Fig. 2), with some exceptions. AT (module 17, Nbc43) is similar to AT (module 19, GonP7) from PM100117 and PM100118 BGC (62.4\% similarity). Both acyltransferases are predicted to be specific for methylmalonyl CoA, according to homology predictions (Additional file 1: Figure S12) [40]. However, in their putative biosynthetic pathways, a malonyl CoA extender unit is predicted to be incorporated. A redundant dehydratase was also observed in module 12 , Nbc40. In notonesomycins $\mathrm{A}$ and $\mathrm{B}$, a moiety consisting of 4-amino, 3-hydroxy benzoic acid and two deoxysugars is appended onto C-37 (Fig. 2b). The 4-amino, 3-hydroxy benzoic acid is predicted to be produced by aminobenzoate synthase, a chorismate lyase and a 4-hydroxybenozate 3-monooxygenase, which are encoded by $n b c 57-59$ respectively. Thymidine diphosphate (TDP)-4-keto-6-deoxy-D-glucose is synthesized by glucose-1-phosphate thymidylyltransferase and dTDP-glucose-4,6-dehydratase that are encoded by $n b c 24$ and $n b c 25$ respectively [41]. A putative set of genes $(n b c 15-17)$ encoding for an epimerase, TDP-hexose-3-ketoreductase and TDP-hexose 2, 3-dehydratase are proposed for the biosynthesis of the final two deoxysugars from TDP-4-keto-6-deoxy-D-glucose (Additional file 1: Figure S13). No additional ketoreductase and dehydratase are found for sugar biosynthesis within the cluster, leading us to suspect that $n b c 15-17$ may be promiscuous in their substrate and stereochemistry specificities [18]. O-methylation on the deoxysugar is predicted to occur via a methyltransferase encoded by $n b c 56$. Within the cluster, two putative glycosyltransferases were observed (Nbc18 and Nbc22) (Additional file 1: Figure S14). Nbc18 is a predicted YjiC type glycosyltransferase. Based on the demonstrated flexibility of YjiC [42], we proposed that the two deoxysugar moieties are loaded onto the 4-amino-3-hydroxybenzoic acid by
Nbc18. Subsequently, glycosylation of the $\mathrm{C}-\mathrm{OH}$ of the polyketide is most likely catalyzed by the Nbc22 (Additional file 1: Figure S14).

Genes $n b c 33, n b c 36, n b c 37$ encode for three P450 homologs, which are predicted to participate in the hydroxylation of $\mathrm{C}-16, \mathrm{C}-14$ and the epoxidation of $\mathrm{C}-28$ (Additional file 1: Figure S15). Esterification is also predicted to proceed via PapA5-like alpha/beta-hydrolase acyltransferase, Nbc13, using malonyl-CoA as a substrate. $\mathrm{Nbc1}$ is predicted to be an $S$-adenosylmethionine-dependent methyltransferase responsible for the $C$-methylation of $\mathrm{C}-38$ in the polyketide chain (Additional file 1: Figure S16).

\section{Experimental validation that the described BGC is responsible for the production of notonesomycins $A$ and $B$}

In order to validate that the $\mathrm{BGC}$ described above is related to the production of notonesomycins $\mathrm{A}$ and $\mathrm{B}$, the CRISPR-Cas9 mediated genomic deletion of $n b c 20$ and $n b c 21$ was carried out. As expected, deletion of this cluster segment ablated the production of notonesomycins $\mathrm{A}$ and B (Fig. 2c, Additional file 1: Figure S17).

\section{Increase in yield of production by SARP overexpression}

The presence of a predicted Streptomyces antibiotic regulatory protein (SARP) family regulator (nbc14) encoded in the notonesomycin BGC presented an opportunity to improve metabolite production. Using CRISPR-Cas9mediated genetic editing, we inserted a strong constitutive $k a s O^{*}$ promoter [27] in front of $n b c 14$. Since the insertion is located in the intergenic region between $n b c 13$ and $n b c 14$, a P8 promoter [43] was also inserted in front of $n b c 13$ to minimize disruption to $n b c 13$ expression. Consistent with $n b c 14$ being a transcriptional activator, increased transcription of $n b c 14$ and selected BGC gene was observed in the engineered strain (nbc14 overexpression, OE, mutant) (Fig. 3). In the wild type Streptomyces sp. A793, notonesomycin production was limited in CA10LB media with soluble starch as the sole carbon source, while in SV2 media containing glucose and glycerol, notonesomycin production level was at least 100fold higher than in CA10LB. The engineered strain was grown in SV2 and CA10LB to assess changes in notonesomycin production. Corresponding to the increase in BGC gene expression, 18- and 11-fold increase in notonesomycin A production in SV2 and CA10LB media was observed in the engineered strain (Fig. 3). Similarly, notonesomycin B yields were increased 3- and 12-fold, respectively in SV2 and CA10LB media with $n b c 14$ overexpression. 
a HII H
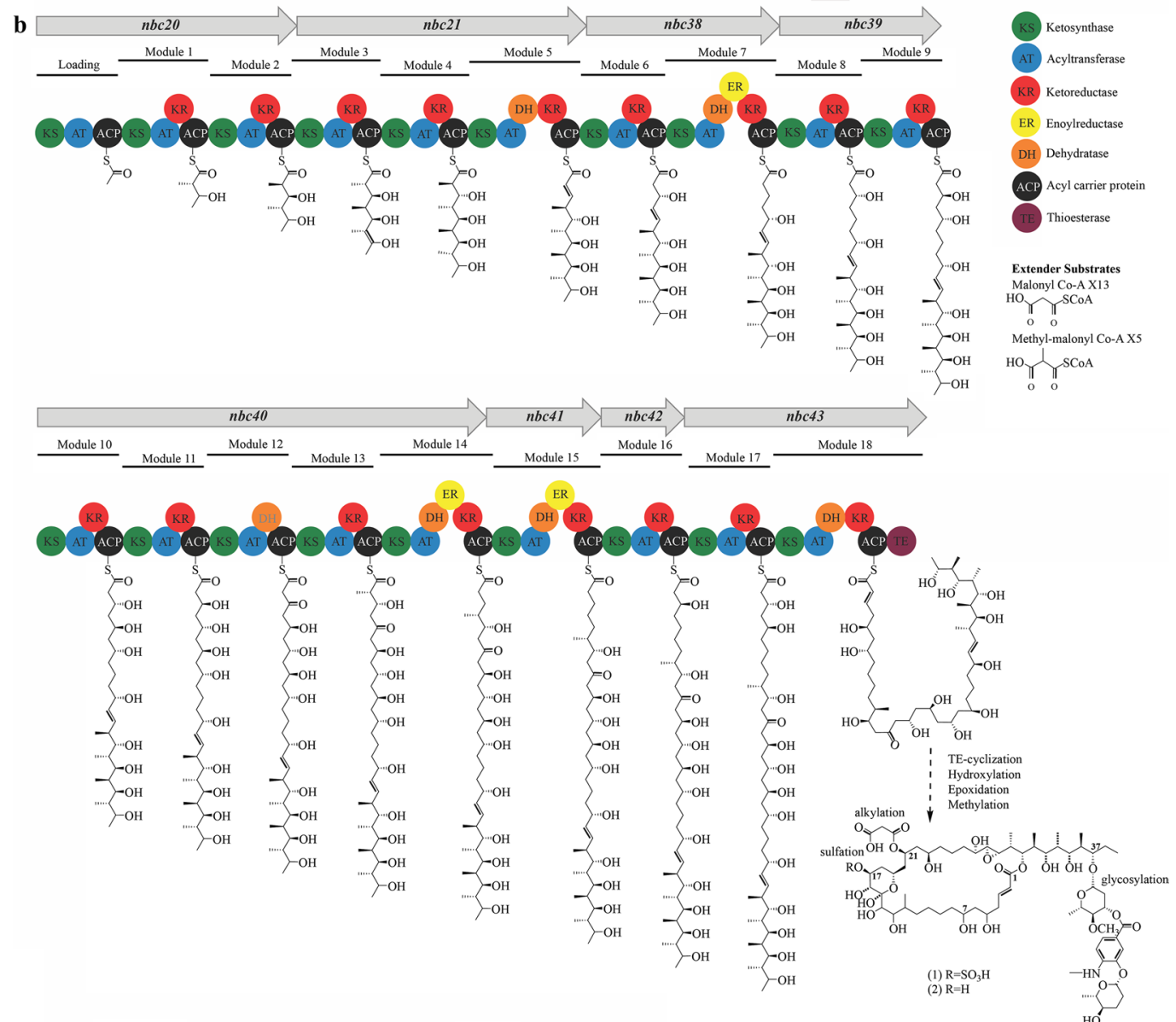

c
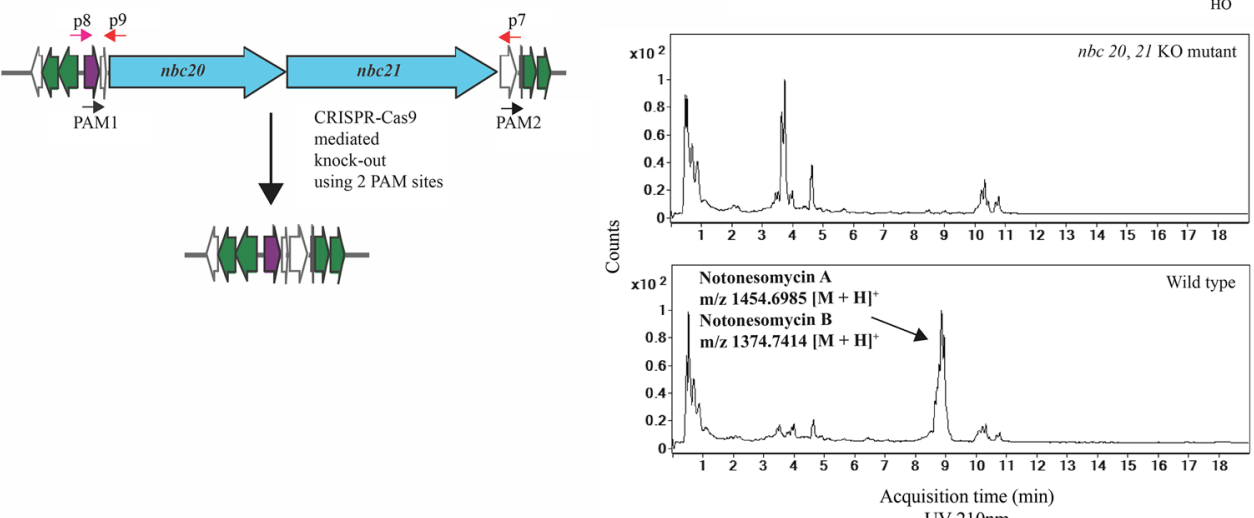

Fig. 2 a Biosynthetic gene cluster arrangement for notonesomycins A and B. b Polyketide synthase assembly line within the notonesomycin BGC. KS, AT, ACP, ER, KR, DH and TE refers to ketosynthase, acyltransferase, acyl carrier protein, enoylreductase, ketoreductase, dehydratase and thioesterase respectively. $\mathbf{c}$ Schematic of CRISPR-Cas9 mediated knock-out (KO) of nbc20 and nbc21. Shown is a UV chromatogram (210 nm) of extracts from the wild type Streptomyces sp. A793 (WT) with the intact notonesomycin gene cluster and the nbc20, 21 double KO mutant (counts). Arrow indicates accumulated notonesomycins A (1) and B (2)

\section{Sulfonate incorporation}

\section{Sulfonate}

to

occur incorporation

via a common is sulfate donor 3'-phosphoadenosine-5' -phosphosulfate (PAPS). Biosynthesis of PAPS is predicted to be directed by an operon encoding for a heterodimeric sulfate adenylytransferase 

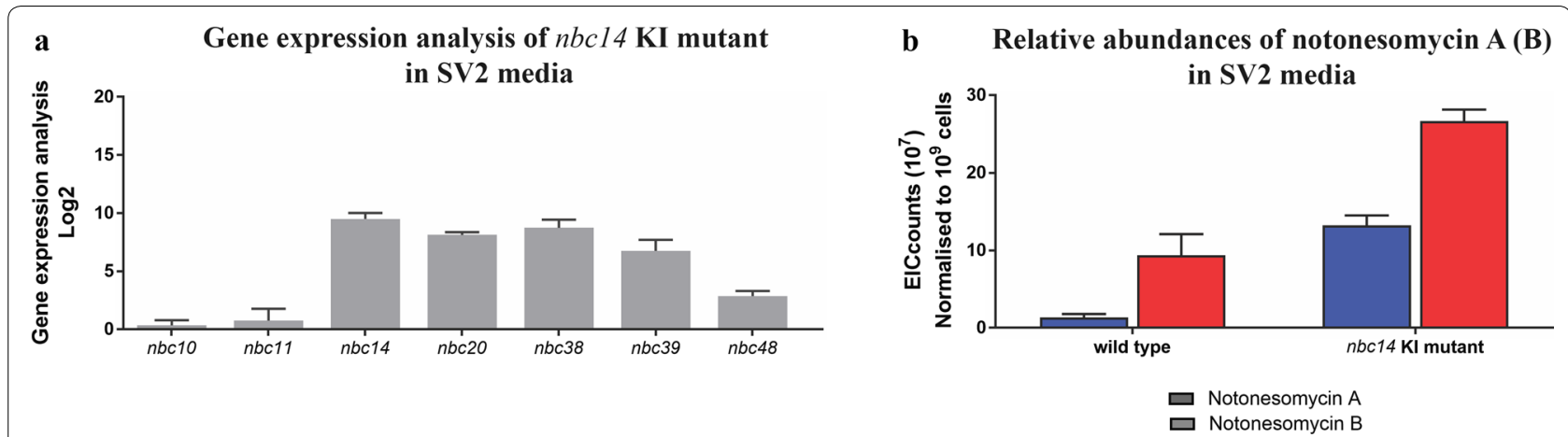

c Gene expression analysis of $n b c 14 \mathrm{KI}$ mutant

d Relative abundances of notonesomycin A (B)
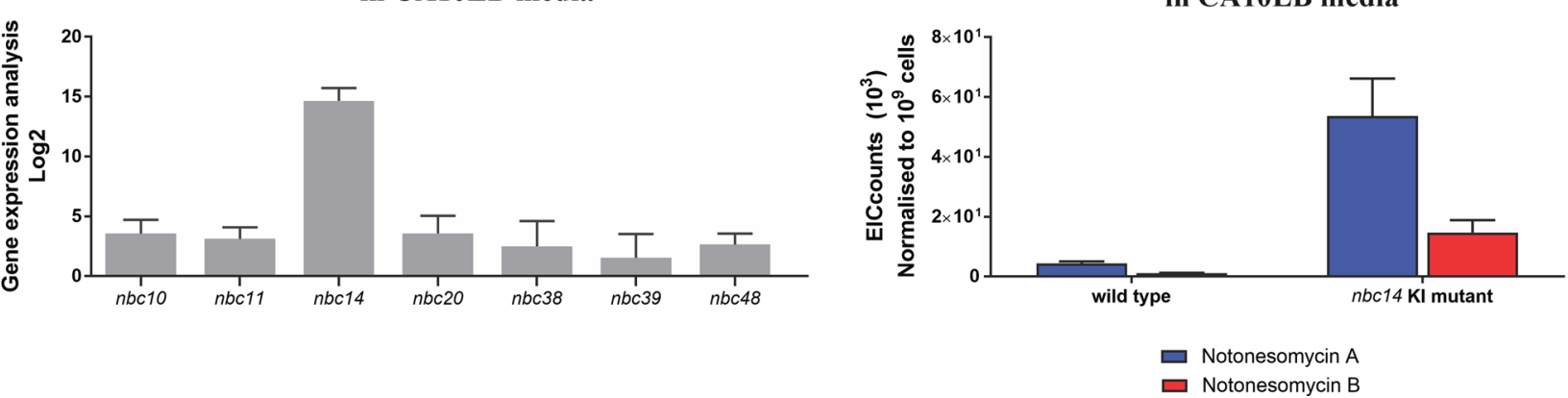

Fig. 3 Relative gene expression associated with notonesomycin biosynthesis of nbc14 overexpression (OE) mutant in a SV2 and c CA10LB media, was determined by RT-qPCR. Log2 fold changes were shown relative to wild type control. Error bars refer to standard deviation for three independent experiments. Relative abundances of notonesomycins A and B of Streptomyces sp. A793 WT and nbc14 OE mutant in b SV2 (EIC counts $10^{7}$ ) and $\mathbf{d}$ CA1OLB media (EIC counts $10^{3}$ ). The increase in notonesomycin production in both media was statistically significant with $\mathrm{P}<0.001$. Counts were obtained from MS-extracted ion chromatograph (EIC) of notonesomycin A $\left(\mathrm{m} / \mathrm{z} 1454.6985[\mathrm{M}+\mathrm{H}]^{+}\right)$and notonesomycin B $(\mathrm{m} / \mathrm{z}$ $\left.1374.7414[\mathrm{M}+\mathrm{H}]^{+}\right)$

(nbc10 and $n b c 11)$, and adenylyl-sulfate kinase $(n b c 9)$, which are similar to CysC, D and $\mathrm{N}$ in E. coli [44] and AziH1-3 of the azinomycin BGC [45], respectively. Sulfonate transfer onto the $\mathrm{C}-17$ accepting hydroxyl group is predicted to be catalyzed by sulfotransferase Stf3 enzyme (Nbc48). Phylogenetic analysis of the sulfotransferases showed that Nbc48 and other sulfotransferases from available Streptomyces genomes formed a clade with Stf3 from Mycobacterium tuberculosis (Additional file 1: Figure S18). Similar to Nbc48, Stf3 is a sulfotransferase found in the sulfomenaquinone BGC, which also includes the PAPS operon [46, 47].

Notably, ratios of sulfated notonesomycin A to the more bioactive notonesomycin B varied significantly in different media conditions. For wild type Streptomyces sp. A793 grown in SV2, notonesomycin B is the major product with a notonesomycin A:B ratio of 1:8 (Fig. 3a). Whilst in NotA media, notonesomycin A is the dominant product with a $3: 1$ notonesomycin $A: B$ ratio (Fig. 4c). Sources of sulfate in microorganisms come from the trans-sulfuration of media amino acids such as methionine, serine, and cysteine [48], as suggested by the presence of a cystathionine gamma-synthase $(n b c 3)$ that catalyzes the biosynthesis of cysteine. In general, the preferred production of notonesomycin A in NotA media by Streptomyces sp. A793 correlated to the higher levels of sulfur-containing amino acids, which is at least fourfold higher in NotA media than SV2 media (Additional file 1: Table S3). To selectively produce notonesomycin B, we deleted $n b c 48$ in Streptomyces sp. A793 and as expected, notonesomycin B was exclusively produced by $n b c 48 \mathrm{KO}$ strains (Fig. 4b, c).

\section{Discussion}

Within the 32-36 membered macrolactones, notonesomycin is notable for its unique sugar moieties and also sulfated functional group. In notonesomycin, its deoxysugars are combined with 4-amino, 3-hydroxy benzoic acid, an exception among the 32-36 membered ring compounds with repertoires of solely deoxysugars combinations. In this study, we not only characterized the biosynthetic pathway of notonesomycin A but we also identified a new non-sulfated analogue, 


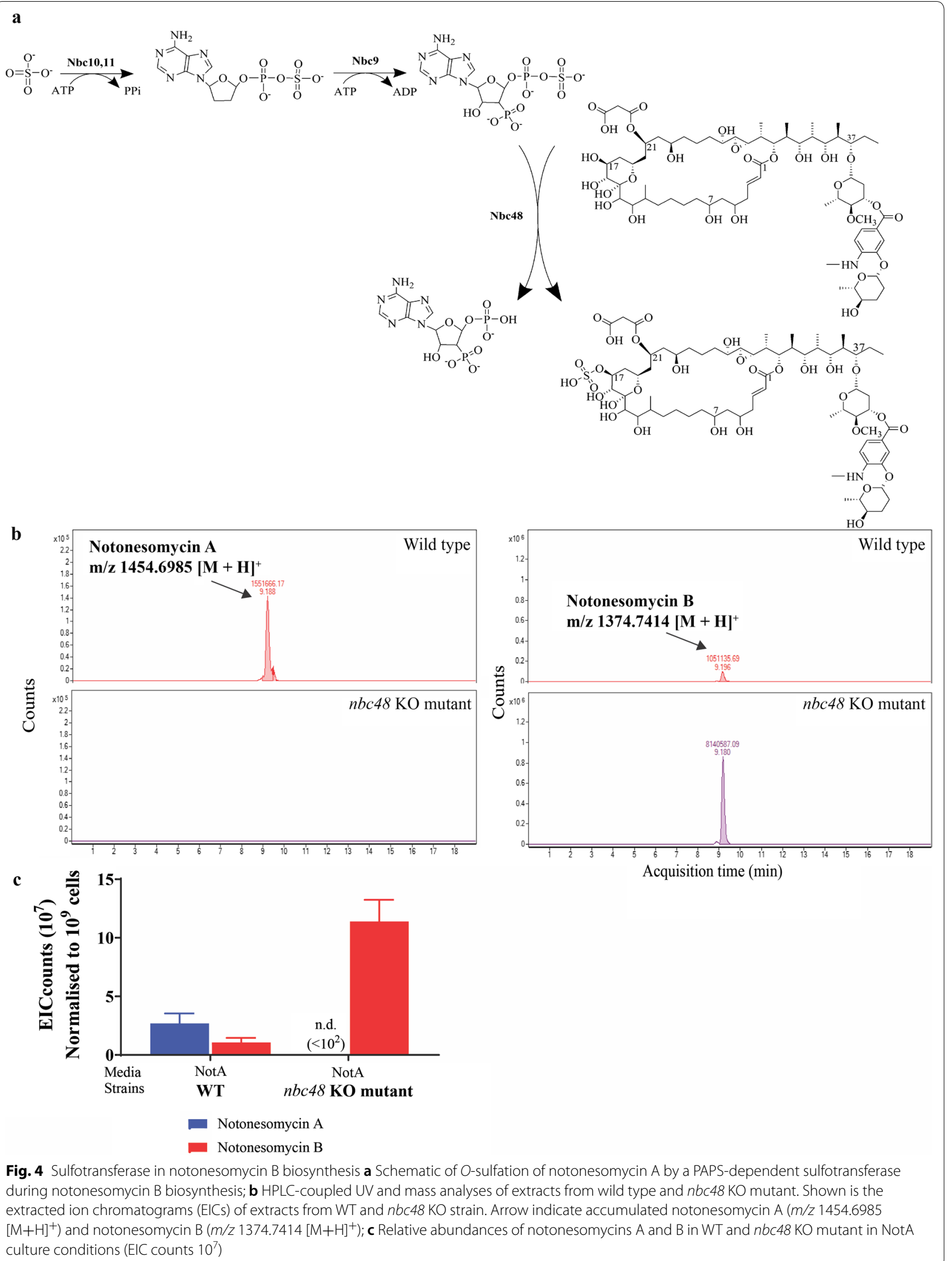


notonesomycin $\mathrm{B}$. We have shown that $\mathrm{O}$-sulfation of the $\mathrm{C}-17$ hydroxyl group reduces its fungicidal activity while increasing its cytotoxicity. In natural product biosynthesis, sulfation is an unusual, poorly understood phenomenon and there are only a handful of naturally occurring sulfated compounds, such as azinomycin [45], glycopeptide A47934 [49], linear polyenes clethramycin and mediomycins [50], liponucleoside antibiotics Caprazamycins [51], $\beta$-lactam sulfated carbapenem MM4550 [52] and deplelides A and B [32]. Enzymatic sulfation has been deployed to increase structural diversity in several classes of natural products [53]. In particular, engineered sulfation of glycopeptide Teicoplanin A47934 [54] yielded bioactive derivatives. With genes encoding both substrates and sulfation reactions elucidated within the notonesomycin BGC, it is possible to engineer sulfation. Here, we used this knowledge to selectively produce the more bioactive notonesomycin analogue. The deletion of Nbc48 sulfotransferase is sufficient to abate notonesomycin A production in favor of notonesomycin B.

Polyketide biosynthesis pathways are modulated by carbon and nitrogen sources through complex regulatory networks involving gene expression, enzyme activities, distribution and abundance of precursors [55-58]. For notonesomycin biosynthesis, the flow of precursors depends on available carbon sources and nutrient utilization, thereby limiting the production yield and relative abundance of the analogues. Yields, analogue distributions and gene expression were vastly different in glycerol and glucose based SV2 culture compared to a starch only CA10LB culture. In addition, through rational engineering, we demonstrated that Streptomyces sp. A793 has not yet reached its full production potential. Overexpression of a pathway specific SARP regulator further improved the yields of notonesomycin A and B in both media.

\section{Conclusion}

In a screen against Candida albicans, Streptomyces sp. A793, which produces notonesomycins A and B, was identified. Compared to notonesomycin A, the non-sulfated notonesomycin B demonstrated higher fungicidal and lower cytotoxicity activity. With the structure and BGC elucidation, along with CRISPR-Cas9-mediated editing, we were able to selectively produce notonesomycin B in Streptomyces sp. A793 and increase the production yields.

\section{Methods}

Bacterial strains, media and cultivation conditions

Notonesomycin-producing strain Streptomyces sp. A793 was obtained from the strain library of A*STAR [5]. The strain was sub-cultured on Bennett's agar (1\% glucose, $0.1 \%$ yeast extract, $0.1 \%$ lab lemco, $5 \%$ glycerol, $0.2 \%$ casitone, $1.5 \%$ agar) for 7 days at $28{ }^{\circ} \mathrm{C}$. Seed culture was grown in SV2 for 7 days at $28{ }^{\circ} \mathrm{C}$ with shaking at $200 \mathrm{rpm}$. Shake flasks fermentation was carried out in CA12LB, CA10LB, SV2 or NotA media [17] (Additional file 1: Table S3). Fermentation was carried out for 9 days at $28{ }^{\circ} \mathrm{C}$ with shaking at $200 \mathrm{rpm}$. Large scale fermentation of $6 \mathrm{~L}$ for $(\mathbf{1})$ isolation was carried out in NotA media and $4 \mathrm{~L}$ fermentation for (2) isolation was carried out in SV2 media. Chemicals and reagents for media preparation were purchased from Sigma or Oxoid. Cell enumeration was determined using drop plate technique and cell viability was carried out using CellTiter-Blue ${ }^{\circledR}$ cell viability assays kits (Promega) according to manufacturer's instructions and fluorescence recorded with a plate reader.

\section{Metabolites extraction and isolation}

For notonesomycin B (2): The culture broths of Streptomyces sp. A793 were combined and centrifuged to separate the supernatant and the mycelia. The combined supernatant was freeze-dried, partitioned with DCM:MeOH: $\mathrm{H}_{2} \mathrm{O}$ (1:1:1). The organic layer was then evaporated to dryness. The dried crude extract $(1.5 \mathrm{~g})$ was re-dissolved in DMSO and separated by $\mathrm{C} 18$ reversed-phase preparative HPLC (solvent $\mathrm{A}: \mathrm{H}_{2} \mathrm{O}+0.1 \%$ $\mathrm{HCOOH}$, solvent B: acetonitrile+ $0.1 \% \mathrm{HCOOH}$; flow rate: $30 \mathrm{~mL} / \mathrm{min}$, gradient conditions: $70: 30$ isocratic for $5 \mathrm{~min} ; 30 \%$ to $70 \%$ of solvent B over $85 \mathrm{~min}$, followed by $70 \%$ to $100 \%$ of solvent B over $10 \mathrm{~min}$, and finally isocratic at $100 \%$ of solvent B for $15 \mathrm{~min}$ ). Fractions eluting at 41-45 min (Fraction A) and 51 min (Fraction B) from HPLC were concentrated and dried under reduce pressure. The dried fraction A from HPLC was then subjected to $\mathrm{C} 18$ reversed-phase preparative HPLC for further purification and yielded $1.75 \mathrm{mg} / \mathrm{L}$ of notonesomycin $\mathrm{B}$ (2). Fraction B (notonesomycin A detected) was not sufficient for further purification. For notonesomycin A (1): The culture broths of Streptomyces sp. A793 were combined and centrifuged to separate the supernatant and the mycelia. The combined supernatant was charged to $10 \mathrm{~cm} \times 8 \mathrm{~cm}$ Sepra C18-E (50 $\mu \mathrm{m}, 65 \AA$, Phenomenex $)$ column. The column was eluted by isocratic gradient of $20 \%, 40 \%, 60 \%, 80 \%$, and $100 \%$ aqueous methanol. The $80 \%$ aqueous methanol fraction was concentrated and dried under reduced pressure to yield $1.6 \mathrm{~g}$ of partially enriched fraction of notonesomycin A (1). The dried extract was then re-dissolved in $2 \mathrm{~mL}$ of $\mathrm{MeOH}$ and further separated by Sephadex LH-20 column (mobile phase: $\mathrm{MeOH}$ ) to give $1.67 \mathrm{mg} / \mathrm{L}$ of notonesomycin A (1). 


\section{Chemical structural data}

The NMR spectra of notonesomycins A and B are provided (Additional file 1: Figures S2-S11).

\section{Notonesomycin A (1)}

Brownish amorphous solid; $[\alpha]_{\mathrm{D}}-25(c 0.9, \mathrm{MeOH})$; $\mathrm{UV}(\mathrm{MeOH}) \lambda_{\max }(\log \varepsilon) 228$ sh (4.27) and 307 (3.91)

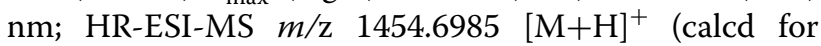
$\left.\mathrm{C}_{68} \mathrm{H}_{111 \mathrm{~N}} \mathrm{O}_{30} \mathrm{~S}+\mathrm{H}, 1454.6984\right) ;{ }^{1} \mathrm{H}$ and ${ }^{13} \mathrm{C}$ NMR data, see Additional file 1: Table S1.

\section{Notonesomycin B (2)}

White amorphous solid; $[\alpha]_{\mathrm{D}}-56$ (c 1.3, MeOH); $\mathrm{UV}(\mathrm{MeOH}) \lambda_{\max }(\log \varepsilon) 229$ sh (3.94) and 309 (3.89) $\mathrm{nm}$; HR-ESI-MS $\mathrm{m} / \mathrm{z}$ 1374.7414 $[\mathrm{M}+\mathrm{H}]^{+}$(calcd for $\left.\mathrm{C}_{68} \mathrm{H}_{111 N} \mathrm{O}_{27}+\mathrm{H}, 1374.7416\right) ;{ }^{1} \mathrm{H}$ and ${ }^{13} \mathrm{C}$ NMR data, see Additional file 1: Table S1.

\section{General experimental procedures}

Optical rotations were recorded on a JASCO P-2000 digital polarimeter. UV spectra were obtained on a GE Healthcare Ultrospec 9000 spectrophotometer. NMR spectra were collected on a Bruker DRX-400 NMR spectrometer with Cryoprobe, using 5-mm BBI $\left({ }^{1} \mathrm{H}, \mathrm{G}-\mathrm{COSY}\right.$, multiplicity-edited G-HSQC, and G-HMBC spectra) or BBO $\left({ }^{13} \mathrm{C}\right.$ spectra) probe heads equipped with z-gradients. Spectra were calibrated to residual protonated solvent signals $\left(\mathrm{CD}_{3} \mathrm{OD} \delta_{\mathrm{H}} 3.30\right.$ and $\mathrm{CD}_{3} \mathrm{OD} \delta_{\mathrm{C}} 49.0$; DMSO- $d_{6} \delta_{\mathrm{H}} 2.49$ and DMSO- $\left.d_{6} \delta_{\mathrm{C}} 39.5\right)$. Preparative HPLC analysis was performed on the Agilent 1260 Infinity Preparative-Scale LC/MS Purification System, completed with Agilent 6130B single quadrupole mass spectrometer for LC and LC/MS Systems. The samples were separated on an Agilent Prep C18 column $(100 \times 30 \mathrm{~mm})$ by gradient elution with a mixture of $0.1 \%$ formic acid in water (solvent $\mathrm{A}$ ) and $0.1 \%$ formic acid in acetonitrile (solvent B). The HR-ESI-MS spectra were acquired on Agilent UHPLC 1290 Infinity coupled to Agilent 6540 accurate-mass quadrupole time-of-flight (QTOF) mass spectrometer equipped with a splitter and an ESI source. The analysis was performed with a $\mathrm{C} 18$ $4.6 \times 75 \mathrm{~mm}, 2.7 \mu \mathrm{m}$ column at flowrate of $2 \mathrm{~mL} / \mathrm{min}$, under standard gradient condition of $0.1 \%$ formic acid in water and $0.1 \%$ formic acid in acetonitrile over $15 \mathrm{~min}$.

\section{Biological assays}

Minimum inhibition concentration (MIC) was determined using the microbroth dilution method according to guidelines of the Clinical Laboratory Standards Institute (CLSI) with slight modifications. Assays were carried out with C. albicans $\mathrm{ATCC}^{\circledR} 90028^{\mathrm{TM}}$ at $2.5 \times 10^{5}$ cells $\mathrm{mL}^{-1}$, A. fumigatus ATCC $^{\circledR} 46645^{\mathrm{TM}}$ at $2.5 \times 10^{4}$ spores $\mathrm{mL}^{-1}$ and both $S$. aureus Rosenbach
ATCC $^{\circledR} 25923^{\mathrm{TM}}$ and Escherichia coli $\left(\right.$ ATCC $^{\circledR} 25922^{\mathrm{TM}}$ ) at $5 \times 10^{5}$ cells $\mathrm{mL}^{-1}$. The cells were incubated with the compounds at $35^{\circ} \mathrm{C}$ for $24 \mathrm{~h}$ (C. albicans) and $48 \mathrm{~h}(A$. fumigatus); and $37{ }^{\circ} \mathrm{C}$ for $24 \mathrm{~h}$ for both bacteria. The effect of the compounds on bacterial growth was evaluated by measuring the optical density at $600 \mathrm{~nm}$ using a microplate reader. Mammalian cell cytotoxicity was assessed with A549 human lung carcinoma cells (ATCC ${ }^{\circledR}{ }^{8} \mathrm{CCL}-185^{\mathrm{TM}}$ ) seeded at 1500 cells well $^{-1}$, while both PANC-1 human pancreatic carcinoma cells $\left(\right.$ ATCC $^{\circledR}$ CRL-1469 $9^{\mathrm{TM}}$ ) and HepG2 human hepatocellular carcinoma cells (ATCC ${ }^{\circledR} \mathrm{HB}-8065^{\mathrm{TM}}$ ) which were both seeded at 2500 cells well $^{-1}$. These cells were treated with the compounds for $72 \mathrm{~h}$ at $37^{\circ} \mathrm{C}$ in the presence of $5 \% \mathrm{CO}_{2}$. PrestoBlue $^{\mathrm{TM}}$ cell viability reagent (Life Technologies) was used to assess the cytotoxic effect of the compounds. Microplates were incubated with this dye for $2 \mathrm{~h}$ before measuring the fluorescence at excitation $560 \mathrm{~nm}$ and emission $590 \mathrm{~nm}$. All assays were performed in triplicate on two different test runs.

\section{Isolation of genomic DNA from Streptomyces sp. A793}

High-quality and molecular weight genomic DNA $(>20 \mathrm{~kb})$ was extracted from Streptomyces sp. A793 with modified CTAB method [59]. Cells were suspended in TE buffer ( $10 \mathrm{mM}$ Tris; $1 \mathrm{mM}$ EDTA, $\mathrm{pH}$ 8.0) containing $20 \mu \mathrm{L}$ of lysozyme $\left(100 \mathrm{mg} \mathrm{mL}^{-1}\right)$ and $15 \mu \mathrm{L}$ of RNase $\left(10 \mathrm{mg} \mathrm{mL}^{-1}\right)$ at $37^{\circ} \mathrm{C}$ overnight. Subsequent procedures of the CTAB method were carried out, followed by phenol-chloroform purification. An additional purification step was carried out using MagBind ${ }^{\circledR}$ RxnPure Plus (OMEGA bio-tek) as per manufacturer's protocol.

\section{Genome sequencing, putative biosynthetic gene cluster annotation and analysis}

Genome sequencing was performed with the Pacific Biosciences (PacBio) RSII. Purified genomic DNA was sheared to approximately $20 \mathrm{~kb}$ using a g-Tube (Covaris). A SMRTbell library was prepared according to manufacturer's instructions, loaded with a MagBead bound library protocol onto two SMRTCells at 0.125 and $0.3 \mathrm{nM}$, and sequenced using the P5-C3 chemistry on the PacBio RSII instrument (Pacific Biosciences) with a 180 min movie time. De novo assembly was performed with the Hierarchical Genome Assembly Process 3 (HGAP3) [60] in the SMRT Analysis suite (version 2.3) using all default parameters. Putative BGCs were identified using antiSMASH 3.0 server [38].

\section{Species identification}

A nucleotide BLAST search of the 16S rRNA obtained from the A793 genome sequence against the NCBI 16S 
ribosomal RNA database [39] revealed that their copies shared $99.7 \%$ to $99.9 \%$ sequence identity ( $E$-value $=0.0$ for all hits) to $16 \mathrm{~S}$ rRNAs of S. armeniacus strain JCM 3070 (accession numbers NR_112046 and NR_112047) covering a length of 1530 nucleotides. In addition, we found a $100 \%$ identity match of a 1330 nucleotide sequence stretch of the A793 strains' 16S rRNAs to the 16S rRNA partial sequence available in the draft genome of $S$. armeniacus strain ATCC 15676 (accession CP031320; [61]). This evidence is further supported by the finding that the nucleotide sequences of four housekeeping genes, rpoB, $\mathrm{dnaK}$, atpD, and recA, found in both genomes are $100 \%$ identical. Consequently, strain A793 was identified to be closely associated to S. armeniacus.

\section{Protein annotation and analysis}

The identification of open reading frames (ORFs) was obtained with an in-house pipeline that takes into account the gene predictions by Prodigal 2.6.2 [62], Glimmer 3.02 [63, 64] and GeneMark 3.26 [65]. BLASTp searches against the NCBI non-redundant sequence database [39] were carried out for the Nbc1-59 functional annotation based on sequence homology (Additional file 1: Table S2). Proteins without a significant hit were further analysed with ANNOTATOR [66] indicating their small size with considerable amount of low complexity and predicted disordered regions. The sequence boundaries for the modules and domains of the polyketides were based on the antiSMASH predictions. Protein and domain sequences were aligned with different MAFFT algorithms [67] and phylogenetic trees were generated with Maximum Likelihood method based on the JTT matrix-based model [68] with MEGA7 [69].

\section{Construction of genome editing plasmids}

All DNA manipulations were carried out in E. coli DH5 $\alpha$ or OmniMAX ${ }^{\mathrm{TM}}$ (Thermo Fisher). Primers used in this study are listed in Additional file 1: Table S4. Restriction enzymes were obtained from New England Biolabs. Protospacers were first inserted into pCRISPomyces-2 plasmids [29] via BbsI-mediated Golden Gate assembly before the respective homology flanks were inserted via Gibson assembly. The protocol for plasmid construction was previously described [70].

\section{Interspecies conjugation}

Promoter knock-in constructs are transformed into conjugating $E$. coli strains and colonies were picked into LB with $50 \mathrm{mg} / \mathrm{L}$ apramycin (Sigma). A diaminopimelic acid (DAP) negative ET12567/pUZ8002 donor strain was used [71]. Overnight cultures were diluted 1:100 into fresh $\mathrm{LB}$ with apramycin and grown to an $\mathrm{OD}_{600}$ of 0.4-0.6. $400 \mu \mathrm{L}$ of the culture was pelleted, washed twice and resuspended in LB without apramycin. The washed $E$. coli cells were then mixed with spores at 1:5 volume ratio and spotted on R2 without sucrose plates. After incubation for $16-20 \mathrm{~h}$ at $30{ }^{\circ} \mathrm{C}$, the plates were flooded with nalidixic acid and apramycin and incubated until exconjugants appear. Exconjugants were streaked onto MGY plates containing apramycin at $30{ }^{\circ} \mathrm{C}$ followed by re-streaking to MGY plates at $37^{\circ} \mathrm{C}$ to cure the CRISPRCas9 plasmid containing a temperature-sensitive origin of replication. Apramycin-sensitive clones growing at $37{ }^{\circ} \mathrm{C}$ were then subjected to validation of promoter knock-in and genome editing as described below.

\section{Validation of engineered strains}

Genomic DNA from wild type and exconjugants from the indicated strains were isolated from liquid cultures using the Blood and Tissue DNeasy kit (Qiagen) after pretreating the cells with $20 \mathrm{mg} / \mathrm{mL}$ lysozyme for $30 \mathrm{~min}$ at $37^{\circ} \mathrm{C}$. PCR was performed using control primers beyond the homology regions or knock-in specific primers (Additional file 1: Table S4) with KODXtreme Taq polymerase (Millipore). Where indicated, PCR products were subjected to digest with specific restriction enzymes to differentiate between PCR products of wild type genomic sequences and successful genome editing by knock-ins. Positive samples were validated by Sanger sequencing. Oligos used for PCR and sequencing are listed in Additional file 1: Table S4.

\section{Quantitative real-time reverse transcription polymerase chain reaction (RT-qPCR) analysis of notonesomycin biosynthetic gene cluster}

Total RNA from wild type and engineered Streptomyces sp. A793 were isolated using RNeasy Midi Kit (Qiagen) after 9 days growth and treated with TURBO ${ }^{\mathrm{TM}}$ DNase (Ambion). The quality of purified RNA was determined on an Agilent 2100 bioanalyzer (Agilent Technologies, Santa Clara, CA, USA). DNA free RNA samples were used for first strand cDNA synthesis with random hexamers using iScript $^{\mathrm{TM}}$ (Biorad) reverse transcription supermix. RT-qPCR was performed on Applied Biosystems $^{\text {TM }}$ QuantStudio $^{\text {TM }} 6$ Flex Real-Time PCR System using SYBR FAST qPCR master mix (KAPA). Analysis was carried out with QuantStudio ${ }^{\text {TM }}$ Real-Time PCR Software, Version 1.3. The relative abundance of transcripts was calculated by delta-delta CT relative quantitation method/comparative threshold cycle (CT) method [72]. The average CT of housekeeping $r p o B, h r d B, \operatorname{rec} A$ and $a t p B$ genes of Streptomyces sp. A793 was used as endogenous reference to normalize gene expression of each target gene (Additional file 1: Table S5). Triplicates of three biological repeats were performed per condition. 


\section{Mass spectroscopy analysis of gene deletion and insertion mutants}

A $10 \mathrm{~mL}$ culture was freeze dried and extracted with equal volume of methanol and sonicated for $10 \mathrm{~min}$. A wet equivalent of the extract was centrifuged and injected into LC-QTOF for analysis. The HRESIMS spectra were acquired on Agilent UHPLC 1290 Infinity coupled to Agilent 6540 accurate-mass quadrupole time-of-flight (QTOF) mass spectrometer equipped with a splitter and an ESI source. The analysis was performed with a $\mathrm{C} 18$ $4.6 \times 75 \mathrm{~mm}, 2.7 \mu \mathrm{m}$ column at flowrate of $2 \mu \mathrm{mL} / \mathrm{min}$, under standard gradient condition of $100 \%$ water with $0.1 \%$ formic acid to $100 \%$ acetonitrile with $0.1 \%$ formic acid over $15 \mathrm{~min}$. The typical QTOF operating parameters were as follows: positive ionization mode; sheath gas nitrogen, $12 \mathrm{~L} / \mathrm{min}$ at $295{ }^{\circ} \mathrm{C}$; drying gas nitrogen flow, $8 \mathrm{~L} / \mathrm{min}$ at $275^{\circ} \mathrm{C}$; nebulizer pressure, 30 psig; nozzle voltage, $1.5 \mathrm{kV}$; capillary voltage, $4 \mathrm{kV}$. Lock masses in positive ion mode: purine ion at $\mathrm{m} / z 121.0509$ and HP-921 ion at $m / z 922.0098$.

Pairwise comparisons between means abundances of the compounds detected from the mutant and wild type strains were carried out using a Student t-test (two tailed, unpaired) where the null hypothesis states that the means are equal. The difference between the mutant and wild type strains is considered statistically significant if the Student t-test gives a $\mathrm{P}$ value $<0.05$.

\section{Supplementary information}

Supplementary information accompanies this paper at https://doi. org/10.1186/s12934-020-01328-x.

Additional file 1: Table S1. NMR spectral data ${ }^{a}$ of notonesomycin A (1) and notonesomycin B (2). Table S2. Annotation of 59 ORFs of the notonesomycin BGC by sequence homology searches using BLASTp against the NCBI nr database. Table S3. Media compositions used in shake flask fermentation. Table S4. Oligos used in this study. Table S5. List of primers used for RT-qPCR. Figure S1. Structure and gross structures of notonesomycins. Selected HMBC correlations of $\mathbf{1}$ and $\mathbf{2}$. Figure $\mathbf{S 2} .{ }^{13} \mathrm{C}$ NMR spectrum (methanol- $d_{4}, 100 \mathrm{MHz}$ ) of Notonesomycin A (1). Figure S3. ${ }^{1} \mathrm{H}$ NMR spectrum (methanol- $d_{4}, 400 \mathrm{MHz}$ ) of Notonesomycin A (1). Figure S4. COSY spectrum (methanol- $d_{4}, 400 \mathrm{MHz}$ ) of Notonesomycin A (1). Figure S5. HSQC spectrum (methanol- $d_{4}, 400 \mathrm{MHz}$ ) of Notonesomycin A (1). Figure S6. HMBC spectrum (methanol- $d_{4}, 400 \mathrm{MHz}$ ) of Notonesomycin A (1). Figure S7. ${ }^{13} \mathrm{C}$ NMR spectrum (methanol- $d_{4}, 100 \mathrm{MHz}$ ) of Notonesomycin B (2). Figure S8. ${ }^{1} \mathrm{H}$ NMR spectrum (methanol- $d_{4}$, $400 \mathrm{MHz}$ ) of Notonesomycin B (2). Figure S9. COSY spectrum (methanol$d_{4}, 400 \mathrm{MHz}$ ) of Notonesomycin B (2). Figure S10. HSQC spectrum (methanol- $d_{4}, 400 \mathrm{MHz}$ ) of Notonesomycin B (2). Figure S11. HMBC spectrum (methanol- $d_{4}, 400 \mathrm{MHz}$ ) of Notonesomycin B (2). Figure S12. Phylogenetic analysis of 59 acyltransferases (AT) amino acid sequences from notonesomycin (Ntc AT), brasilinolides (Nbr AT), PM100117 and PM100118 (GonP AT) BGCs. Figure S13. Proposed biosynthesis pathways for A) 4-amino 3-hydroxybenzoic acid and B) deoxysugars. Figure S14. Sequence analysis of glycosyltransferases $\mathrm{Nbc1} 8$ and $\mathrm{Nbc} 22$ from the notonesomycin BGC with known glycosyltransferases. Figure S15. Sequence analysis of cytochrome P450 enzymes (Nbc33, Nbc36 and $\mathrm{Nbc37}$ ) from the notonesomycin BGC with other cytochrome P450 with either hydroxylation or epoxidation function. Figure S16. Sequence analysis of methyltransferases $\mathrm{Nbc1}$ and $\mathrm{Nbc56}$ from Streptomyces sp.
A793 present in the notonesomycin BGC with other known $\mathrm{O}-, \mathrm{N}$ - and C-methyltransferases. Figure S17. LC-MS spectra (base peak chromatogram, BPC) for wild type and $n b c 20$ and $n b c 21$ double KO mutant. Figure S18. Sequence analysis of sulfotransferase Nbc48 from the notonesomycin BGC with sulfotransferases that have been associated with other BGCs.

\section{Abbreviations}

NP: Natural products; BGC: Biosynthetic gene clusters; PKS: Polyketides synthase; MIC: Minimum inhibition concentration; $I_{50}$ : Half maximal inhibitory concentration; IC $C_{90}$ : 90\% maximal inhibitory concentration; QTOF: Quadrupole time-of-flight; KO: Knock-out; OE: Over-expression; EIC: Extracted ion chromatograph; SARP: Streptomyces antibiotic regulatory protein; NOL: Natural Organism Library; CT: Cycle threshold; TDP: Thymidine diphosphate; ORF: Open reading frame.

\section{Acknowledgements}

The authors gratefully acknowledge the late Sydney Brenner for his discussion and support. We also thank Raquel Peh for her technical assistance.

\section{Authors' contributions}

FG, FTW-Manuscript writing, experimental plan and procedures, and data analysis; FG, TRL, ZT_-Spore preparation and antibiotics sensitivities testing, preparation of samples for LC-MS, RNA extractions and CDNA synthesis, carried out qRT-PCR; FG, TRL, ZT, VN, CYL—Large scale fermentation for compounds isolation; $\mathrm{SC}$ - Biological activities testing of isolated compounds; $\mathrm{KNL}$, CEN, YK-Compound isolation and purification, NMR structural elucidation and LC-MS analysis; VN, AL_DNA extraction for genome sequencing; $\mathrm{HZ}$, AL, SLC-PacBio Library Prep, genome sequencing and assembly; SSH, FLS, BE, FE-Protein annotation and bioinformatics analyses; EH, WLY, MMZ, FTWKnockin/Knockout systems using CRISPR-cas9; SBN-Provided supervision and resources. All authors reviewed the final manuscript. All authors read and approved the final manuscript.

\section{Funding}

This work was supported by the Agency for Science, Technology and Research (A*STAR), Singapore. WLY, EH, MMZ, FTW are supported by National Research Foundation, Singapore [NRF2013-THE001-094].

\section{Availability of data and materials}

All data generated or analyzed during this study are included in this published article [and its supplementary information files]. Cluster sequence has been deposited in NCBI GenBank under accession number MN586816.

Ethics approval and consent to participate

Not applicable.

\section{Consent for publication}

Not applicable.

\section{Competing interests}

The authors declare that they have no competing interests.

\section{Author details}

${ }_{1}^{1}$ Bioinformatics Institute, A*STAR, 30 Biopolis Street, \#07-01 Matrix, Singapore 138671, Singapore. ${ }^{2}$ Metabolic Engineering, Functional Molecules \& Polymers, Institute of Chemical and Engineering Sciences, A*STAR, 31 Biopolis Way, Nanos \#01-01, Singapore 138669, Singapore. ${ }^{3}$ Molecular Engineering Laboratory, Institute of Bioengineering and Nanotechnology, A*STAR, 31 Biopolis Way, Nanos, Singapore 138669, Singapore. ${ }^{4}$ Genome Institute of Singapore, A*STAR, 60 Biopolis Street, Genome \#02-01, Singapore 138672, Singapore. ${ }^{5}$ Department of Medicine, Yong Loo Lin School of Medicine, National University of Singapore, 1 E Kent Ridge Road, NUHS Tower Block, Level 10, Singapore 119228, Singapore. ${ }^{6}$ School of Computer Science and Engineering, Nanyang Technological University (NTU), 50 Nanyang Drive, Singapore 637553, Singapore. ${ }^{7}$ Biotransformation Innovation Platform, A*STAR, 61 Biopolis Drive, Proteos Level 4, Singapore 138673, Singapore. ${ }^{8}$ Institute of Molecular and Genomic Medicine, National Health Research Institutes, Miaoli County, Taiwan, R.O.C. 
Received: 10 October 2019 Accepted: 12 March 2020

Published online: 19 March 2020

\section{References}

1. Newman DJ, Cragg GM. Natural products as sources of new drugs from 1981 to 2014. J Nat Prod. 2016;79:629-61.

2. Bérdy J. Thoughts and facts about antibiotics: where we are now and where we are heading. J Antibiot (Tokyo). 2012;65:385-95.

3. Parkinson El, Bair JS, Nakamura BA, Lee HY, Kuttab HI, Southgate EH, et al. Deoxynybomycins inhibit mutant DNA gyrase and rescue mice infected with fluoroquinolone-resistant bacteria. Nat Commun. 2015;6:6947.

4. Rodrigues T, Reker D, Schneider P, Schneider G. Counting on natural products for drug design. Nat Chem. 2016;8:531-41.

5. Ng SB, Kanagasundaram Y, Fan H, Arumugam P, Eisenhaber B, Eisenhaber F. The $160 \mathrm{~K}$ Natural Organism Library, a unique resource for natural products research. Nat Biotechnol. 2018;36:570-3.

6. Yoganathan K, Cao S, Crasta SC, Aitipamula S, Whitton SR, Ng S, et al. Microsphaerins A-D, four novel benzophenone dimers with activity against MRSA from the fungus Microsphaeropsis sp. Tetrahedron. 2008:64:10181-7.

7. Rho J-R, Subramaniam G, Choi H, Kim E-H, Ng SP, Yoganathan K, et al. Gargantulide A, a complex 52-membered macrolactone showing antibacterial activity from Streptomyces sp. Org Lett. 2015;17:1377-80.

8. Sirota FL, Goh F, Low K-N, Yang L-K, Crasta SC, Eisenhaber B, et al. Isolation and Identification of an anthracimycin analogue from Nocardiopsis kunsanensis, a halophile from a saltern, by genomic mining strategy. J Genomics. 2018;6:63-73.

9. Yoganathan K, Yang L, Rossant C, Huang Y, Ng S, Butler MS, et al. Cochlioquinones and epi-cochlioquinones: antagonists of the human chemokine receptor CCR5 from Bipolaris brizae and Stachybotrys chartarum. J Antibiot (Tokyo). 2004;57:59-63.

10. Vallabhaneni S, Mody RK, Walker T, Chiller T. The global burden of fungal diseases. Infect Dis Clin North Am. 2016:30:1-11.

11. Guinea J. Global trends in the distribution of Candida species causing candidemia. Clin Microbiol Infect. 2014;20(Suppl 6):5-10.

12. Paulussen C, Hallsworth JE, Álvarez-Pérez S, Nierman WC, Hamill PG, Blain $D$, et al. Ecology of aspergillosis: insights into the pathogenic potency of Aspergillus fumigatus and some other Aspergillus species. Microb Biotechnol. 2016;10:296-322.

13. Brown GD, Denning DW, Gow NAR, Levitz SM, Netea MG, White TC. Hidden killers: human fungal infections. Sci Transl Med. 2012;4:165rv13.

14. Sun S, Lui Q, Han L, Ma Q, He S, Li X, et al. Identification and characterization of Fusarium proliferatum, a new species of fungi that cause fungal keratitis. Sci Rep. 2018:8:4859.

15. Smith KD, Achan B, Hullsiek KH, McDonald TR, Okagaki LH, Alhadab $A A$, et al. Increased antifungal drug resistance in clinical isolates of Cryptococcus neoformans in Uganda. Antimicrob Agents Chemother. 2015;59:7197-204.

16. Sharma C, Kumar R, Kumar N, Masih A, Gupta D, Chowdhary A. Investigation of multiple resistance mechanisms in voriconazole-resistant AspergilIus flavus clinical isolates from a Chest Hospital Surveillance in Delhi, India. Antimicrob Agents Chemother. 2018;62:e01928-17.

17. Sasaki T, Furihata K, Shimazu A, Seto H, Iwata M, Watanabe T, et al. A novel macrolide antibiotic, notonesomycin A. J Antibiot (Tokyo). 1986;39:502-9.

18. Chiu H-T, Weng C-P, Lin Y-C, Chen K-H. Target-specific identification and characterization of the putative gene cluster for brasilinolide biosynthesis revealing the mechanistic insights and combinatorial synthetic utility of 2-deoxy-l-fucose biosynthetic enzymes. Org Biomol Chem. 2016;14:1988-2006.

19. Tanaka Y, Komaki H, Yazawa K, Mikami Y, Nemoto A, Tojyo T, et al. Brasilinolide A, a new macrolide antibiotic produced by Nocardia brasiliensis: producing strain, isolation and biological activity. J Antibiot (Tokyo). 1997;50:1036-41.

20. Robbins N, Spitzer M, Wang W, Waglechner N, Patel DJ, O'Brien JS, et al. Discovery of ibomycin, a complex macrolactone that exerts antifungal activity by impeding endocytic trafficking and membrane function. Cell Chem Biol. 2016;23:1383-94.
21. Helaly SE, Kulik A, Zinecker H, Ramachandaran K, Tan GYA, Imhoff JF, et al. Langkolide, a 32-membered macrolactone antibiotic produced by Streptomyces sp. Acta 3062. J Nat Prod. 2012;75:1018-24.

22. Wan Z, Fang W, Shi L, Wang K, Zhang Y, Zhang Z, et al. Novonestmycins A and $\mathrm{B}$, two new 32-membered bioactive macrolides from Streptomyces phytohabitans HBERC-20821. J Antibiot (Tokyo). 2015;68:185-90.

23. Salcedo RG, Olano C, Gómez C, Fernández R, Braña AF, Méndez C, et al. Characterization and engineering of the biosynthesis gene cluster for antitumor macrolides PM100117 and PM100118 from a marine actinobacteria: generation of a novel improved derivative. Microb Cell Factories. 2016;15:44.

24. Salcedo RG, Olano C, Fernández R, Braña AF, Méndez C, de la Calle F, et al. Elucidation of the glycosylation steps during biosynthesis of antitumor macrolides PM100117 and PM100118 and engineering for novel derivatives. Microb Cell Factories. 2016;15:187.

25. Blin K, Medema MH, Kottmann R, Lee SY, Weber T. The antiSMASH database, a comprehensive database of microbial secondary metabolite biosynthetic gene clusters. Nucleic Acids Res. 2017;45:D555-9.

26. Gomez-Escribano JP, Alt S, Bibb MJ. Next generation sequencing of actinobacteria for the discovery of novel natural products. Mar Drugs. 2016;14:78

27. Zhang MM, Wong FT, Wang Y, Luo S, Lim YH, Heng E, et al. CRISPR-Cas9 strategy for activation of silent Streptomyces biosynthetic gene clusters. Nat Chem Biol. 2017;13:607-9.

28. Tong Y, Charusanti P, Zhang L, Weber T, Lee SY. CRISPR-Cas9 based engineering of actinomycetal genomes. ACS Synth Biol. 2015;4:1020-9.

29. Jia H, Zhang L, Wang T, Han J, Tang H, Zhang L. Development of a CRISPR/ Cas9-mediated gene-editing tool in Streptomyces rimosus. Microbiol Read Engl. 2017;163:1148-55

30. Cobb RE, Wang Y, Zhao H. High-efficiency multiplex genome editing of Streptomyces species using an engineered CRISPR/Cas system. ACS Synth Biol. 2015;4:723-8.

31. Huang $H$, Zheng G, Jiang W, Hu H, Lu Y. One-step high-efficiency CRISPR/ Cas9-mediated genome editing in Streptomyces. Acta Biochim Biophys Sin. 2015;47:231-43.

32. Takeuchi T, Hatano M, Umekita M, Hayashi C, Wada S-I, Nagayoshi M, et al. ATP depletion assay led to the isolation of new 36-membered polyol macrolides deplelides A and B from Streptomyces sp. MM581-NF15. Org Lett. 2017;19:4207-10.

33. Komatsu K, Tsuda M, Tanaka Y, Mikami Y, Kobayashi J. Absolute stereochemistry of immunosuppressive macrolide brasilinolide $A$ and its new congener brasilinolide C. J Org Chem. 2004;69:1535-41.

34. Sasaki T, Furihata K, Nakayama H, Seto H, Otake N. The structure of a novel macrolide antibiotic, notonesomycin A. Tetrahedron Lett. 1986;27:1603-6.

35. Hideyuki S, Yasushi T, Katsukiyo Y, Yuzuru M, Jun'ichi K. Brasilinolide A, new immunosuppressive macrolide from actinomycete Nocardia brasiliensis. Tetrahedron. 1996;52:9031-4

36. Wan Z, Fang W, Shi L, Wang K, Zhang Y, Zhang Z, et al. Novonestmycins A and B, two new 32-membered bioactive macrolides from Streptomyces phytohabitans HBERC-20821. J Antibiot. 2015;68:185-90.

37. Overbeek R, Olson R, Pusch GD, Olsen GJ, Davis JJ, Disz T, et al. The SEED and the rapid annotation of microbial genomes using subsystems technology (RAST). Nucleic Acids Res. 2014;42:D206-14.

38. Weber T, Blin K, Duddela S, Krug D, Kim HU, Bruccoleri R, et al. AntiSMASH 3.0-a comprehensive resource for the genome mining of biosynthetic gene clusters. Nucleic Acids Res. 2015;43:W237-43.

39. NCBI Resource Coordinators. Database resources of the National Center for Biotechnology Information. Nucleic Acids Res. 2018;46:D8-13.

40. Salcedo RG, Olano C, Gómez C, Fernández R, Braña AF, Méndez C, de la Calle F, Salas JA. Characterization and engineering of the biosynthesis gene cluster for antitumor macrolides PM100117 and PM100118 from a marine actinobacteria: generation of a novel improved derivative. Microb Cell Factories. 2016;15-62:44.

41. Wang L, White RL, Vining LC. Biosynthesis of the dideoxysugar component of jadomycin B: genes in the jad cluster of Streptomyces venezuelae ISP5230 for L-digitoxose assembly and transfer to the angucycline aglycone. Microbiol Read Engl. 2002;148:1091-103.

42. Pandey RP, Gurung RB, Parajuli P, Koirala N, Tuoi LT, Sohng JK. Assessing acceptor substrate promiscuity of YjiC-mediated glycosylation toward flavonoids. Carbohydr Res. 2014;393:26-31. 
43. Luo Y, Zhang L, Barton KW, Zhao H. Systematic identification of a panel of strong constitutive promoters from Streptomyces albus. ACS Synth Biol. 2015:4:1001-10.

44. Leyh TS, Taylor JC, Markham GD. The sulfate activation locus of Escherichia coli K12: cloning, genetic, and enzymatic characterization. J Biol Chem. 1988;263:2409-16.

45. Zhao Q, He Q, Ding W, Tang M, Kang Q, Yu Y, et al. Characterization of the azinomycin B biosynthetic gene cluster revealing a different iterative type I polyketide synthase for naphthoate biosynthesis. Chem Biol. 2008; 15:693-705.

46. Mougous JD, Senaratne RH, Petzold CJ, Jain M, Lee DH, Schelle MW, et al. A sulfated metabolite produced by stf3 negatively regulates the virulence of Mycobacterium tuberculosis. Proc Natl Acad Sci USA. 2006;103:4258-63.

47. Sogi KM, Holsclaw CM, Fragiadakis GK, Nomura DK, Leary JA, Bertozzi CR. Biosynthesis and regulation of sulfomenaquinone, a metabolite associated with virulence in Mycobacterium tuberculosis. ACS Infect Dis. 2016;2:800-6.

48. Sekowska A, Kung HF, Danchin A. Sulfur metabolism in Escherichic coli and related bacteria: facts and fiction. J Mol Microbiol Biotechnol. 2000:2:145-77.

49. Pootoolal J, Thomas MG, Marshall CG, Neu JM, Hubbard BK, Walsh CT, et al. Assembling the glycopeptide antibiotic scaffold: the biosynthesis of A47934 from Streptomyces toyocaensis NRRL15009. Proc Natl Acad Sci USA. 2002;99:8962-7.

50. Hong H, Samborskyy M, Usachova K, Schnatz K, Leadlay PF. Sulfation and amidinohydrolysis in the biosynthesis of giant linear polyenes. Beilstein J Org Chem. 2017;13:2408-15.

51. Tang X, Eitel K, Kaysser L, Kulik A, Grond S, Gust B. A two-step sulfation in antibiotic biosynthesis requires a type III polyketide synthase. Nat Chem Biol. 2013;9:610-5.

52. Li R, Lloyd EP, Moshos KA, Townsend CA. Identification and characterization of the carbapenem MM 4550 and its gene cluster in Streptomyces argenteolus ATCC 11009. Chembiochem Eur J Chem Biol. 2014;15:320-31.

53. van der Horst MA, Hartog AF, El Morabet R, Marais A, Kircz M, Wever R. Enzymatic sulfation of phenolic hydroxy groups of various plant metabolites by an arylsulfotransferase. Eur J Org Chem. 2015;2015:534-41.

54. Banik JJ, Craig JW, Calle PY, Brady SF. Tailoring enzyme-rich environmental DNA clones: a source of enzymes for generating libraries of unnatural natural products. J Am Chem Soc. 2010;132:15661-70.

55. Schniete JK, Cruz-Morales P, Selem-Mojica N, Fernández-Martínez LT, Hunter IS, Barona-Gómez F, et al. Expanding primary metabolism helps generate the metabolic robustness to facilitate antibiotic biosynthesis in streptomyces. mBio. 2018;9:e02283-17.

56. Romero-Rodríguez A, Rocha D, Ruiz-Villafan B, Tierrafría V, RodríguezSanoja R, Segura-González D, et al. Transcriptomic analysis of a classical model of carbon catabolite regulation in Streptomyces coelicolor. BMC Microbiol. 2016;16:77

57. Jin X-M, Chang Y-K, Lee JH, Hong S-K. Effects of Increased NADPH concentration by metabolic engineering of the pentose phosphate pathway on antibiotic production and sporulation in Streptomyces lividans TK24. J Microbiol Biotechnol. 2017;27:1867-76.
58. Wentzel A, Bruheim P, Øverby A, Jakobsen ØM, Sletta H, Omara WAM, et al. Optimized submerged batch fermentation strategy for systems scale studies of metabolic switching in Streptomyces coelicolor A3(2). BMC Syst Biol. 2012;6:59.

59. Wilson K. Preparation of genomic DNA from bacteria. Curr Protoc Mol Biol. 2001; Chapter 2:Unit 2.4.

60. Chin C-S, Alexander DH, Marks P, Klammer AA, Drake J, Heiner C, et al. Nonhybrid, finished microbial genome assemblies from long-read SMRT sequencing data. Nat Methods. 2013;10:563-9.

61. Labana P, Gosse JT, Boddy CN. Draft genome sequence of the type strain Streptomyces armeniacus ATCC 15676. Microbiol Resour Announc. 2018;7:e01107-18.

62. Hyatt D, Chen G-L, Locascio PF, Land ML, Larimer FW, Hauser LJ. Prodigal: prokaryotic gene recognition and translation initiation site identification. BMC Bioinform. 2010;11:119.

63. Delcher AL, Harmon D, Kasif S, White O, Salzberg SL. Improved microbial gene identification with GLIMMER. Nucleic Acids Res. 1999;27:4636-41.

64. Salzberg SL, Delcher AL, Kasif S, White O. Microbial gene identification using interpolated Markov models. Nucleic Acids Res. 1998;26:544-8.

65. Lukashin AV, Borodovsky M. GeneMark.hmm: new solutions for gene finding. Nucleic Acids Res. 1998;26:1107-15.

66. Eisenhaber B, Kuchibhatla D, Sherman W, Sirota FL, Berezovsky IN, Wong $\mathrm{W}-\mathrm{C}$, et al. The recipe for protein sequence-based function prediction and its implementation in the ANNOTATOR software environment. Methods Mol Biol Clifton NJ. 2016;1415:477-506.

67. Katoh K, Standley DM. MAFFT multiple sequence alignment software version 7: improvements in performance and usability. Mol Biol Evol. 2013;30:772-80.

68. Jones DT, Taylor WR, Thornton JM. The rapid generation of mutation data matrices from protein sequences. Comput Appl Biosci CABIOS. 1992;8:275-82.

69. Kumar S, Stecher G, Tamura K. MEGA7: molecular evolutionary genetics analysis version 7.0 for bigger datasets. Mol Biol Evol. 2016;33:1870-4.

70. Lim YH, Wong FT, Yeo WL, Ching KC, Lim YW, Heng E, et al. Auroramycin: a potent antibiotic from Streptomyces roseosporus by CRISP-Cas9 activation. ChemBioChem. 2018;19:1716-9.

71. Allard N, Garneau D, Poulin-Laprade D, Burrus V, Brzezinski R, Roy S. A diaminopimelic acid auxotrophic Escherichia coli donor provides improved counterselection following intergeneric conjugation with actinomycetes. Can J Microbiol. 2015;61:565-74.

72. Livak KJ, Schmittgen TD. Analysis of relative gene expression data using real-time quantitative PCR and the 2(-Delta Delta $C(T)$ ) Method. Methods San Diego Calif. 2001;25:402-8.

\section{Publisher's Note}

Springer Nature remains neutral with regard to jurisdictional claims in published maps and institutional affiliations.

\footnotetext{
Ready to submit your research? Choose BMC and benefit from:

- fast, convenient online submission

- thorough peer review by experienced researchers in your field

- rapid publication on acceptance

- support for research data, including large and complex data types

- gold Open Access which fosters wider collaboration and increased citations

- maximum visibility for your research: over $100 \mathrm{M}$ website views per year
}

At $\mathrm{BMC}$, research is always in progress.

Learn more biomedcentral.com/submissions 